\title{
LA RESTAURACIÓN DE LA IGLESIA DE SANT JAUME SESOLIVERES. IGUALADA (BARCELONA, ESPAÑA)
}

\author{
(RESTORATION OF SANT JAUME SESOLIVERES CHURCH. IGUALADA, \\ BARCELONA, SPAIN)
}

Antoni González Moreno - Navarro, Arquitecto

Jefe del Servicio del Patrimonio Arquitectónico Local de la Diputación de Barcelona

Fecha de recepción: 25-VIII-96 $128-66$

\section{RESTMEN}

Al iniciarse la intervención, del pequeño templo románico sólo quedaban los restos ruinosos de sus muros, sobre los que se habian construido otros en época moderna. Tras efectuar la excavación arqueológica y los estudios históricos y constructivos del edificio, se planteó una restauración que hiciera inteligible su evolución en cuanto a uso, forma y sistemas constructivos. Dos criterios generales regirian la restauración: devolver al edificio su condición arquitectónica $y$ recuperar episodios formales y constructivos de su historia sin primar una época en detrimento de las demás.

\section{SUMMARY}

At the time of initiating the restoration of this little Romanesque church only some remainings of the ruined walls were left and upon them modern ones had been built. After going through the archeological excavation and the historical studies, a restoration was planned which should make comprehensible its evolution regarding utility, shape and constructive systems. Two general criteria would manage this restoration: to get back the original architecture of the building, and regain the formal and constructive historical episodes giving no priority to one epoch over another.
El lugar de Sant Jaume Sesoliveres se encuentra en el área central de la comarca de Anoia, de la provincia de Barcelona, cerca de la sierra de Montserrat y junto a la autovía Barcelona-Madrid. Hoy se halla en gran parte ocupado por una urbanización de casas unifamiliares aisladas de cierta categoría residencial, presidida por la iglesia que le da nombre, situada en la vertiente sur de una pequeña colina.

La iglesia de Sant Jaume Sesoliveres responde a la tipología de templo románico de una sola nave de planta rectangular y ábside semicircular. Al iniciarse la intervención, sin embargo, del templo sólo quedaban los restos ruinosos de sus muros, rasgados con profundas grietas, sobre los que se habían construido otros en época moderna. Las cubiertas habían desaparecido y los contrafuertes que aguantaban el conjunto estaban deteriorados. En la fachada de poniente se sobreponían cuatro campanarios de espadaña. En el interior se apreciaban muestras de acabados de diversas épocas, con juntas resaltadas, revocos superpuestos o cornisas de molduraje clásico. 
Los estudios históricos y constructivos previos a la intervención arquitectónica ${ }^{1}$ programada a petición del Ayuntamiento de Igualada (propietario del edificio) permitieron reconocer su evolución a lo largo de los siglos. Gracias a la arqueología, su construcción se fechó a finales del siglo XII o principios del XIII. En el siglo XIV fue tapiada la puerta de mediodía, al adosarse una habitación por este lado, y fue ampliada la de poniente. El hundimiento de la bóveda románica y las grietas y desplomes que mostraba la fábrica, probablemente, fueron debidos al terremoto del 2 de febrero de 1428 , que sacudió buena parte de Cataluña.

En la reconstrucción de finales del siglo $\mathrm{XV}$, se adosaron unos contrafuertes en la fachada meridional, se reabrió la puerta de mediodía y se tapió la de poniente, convirtiéndola en hornacina. También en aquella época se construyó una remonta, un porche abierto a tres vientos, por encima de la cornisa románica, sostenido por pilares de piedra, que comportó la eliminación de los restos de la bóveda de cañón de la nave, la construcción de un piso intermedio de vigas y tablazón de madera y una cubierta de cuchillos. Hacia 1632 se construyó una sacristía adosada al lado sur-oriental de la nave. Es posible que fuera entonces cuando se cerrasen los espacios entre los pilares del porche. En el siglo XVIII se efectuaron las últimas reformas importantes. Se sustituyó el piso del siglo XV por unas bóvedas encamonadas, hechas de rasilla y yeso, que arrancaban de una cornisa moldurada, también de yeso, propia del barroco académico de la época, y se levantó una nueva espadaña. A lo largo del siglo XIX sólo se celebró culto de manera esporádica, en una iglesia ya bastante deteriorada. En 1936, al iniciarse la Guerra Civil, el templofue incendiado y permaneció sin cubierta desde entonces.

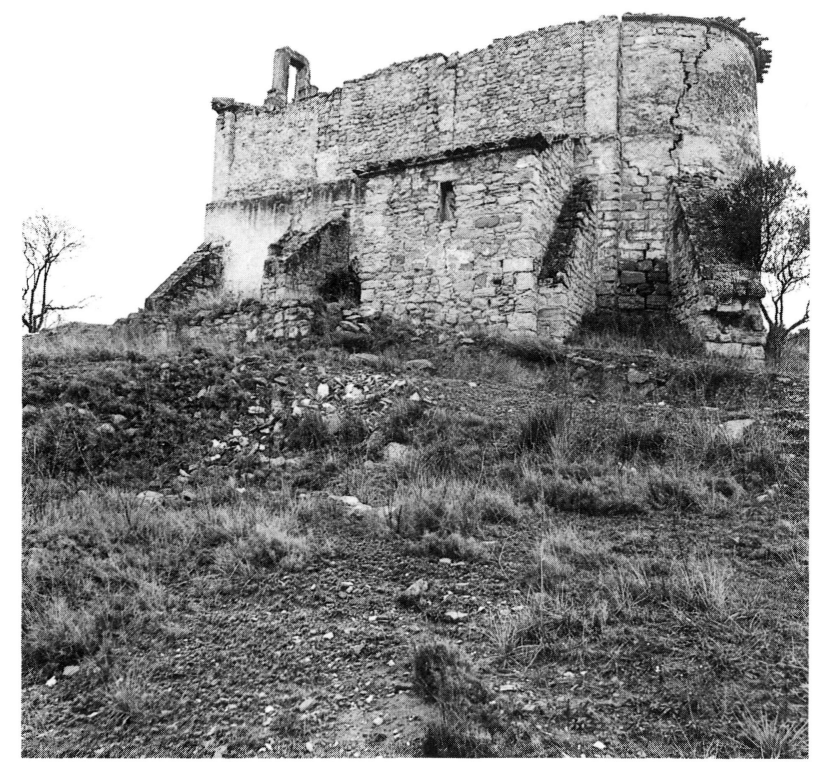

La iglesia vista desde el sudeste, antes de iniciarse los trabajos de restauración (9 de marzo de 1993).

\section{ANALISIS FISICO-CONSTRUCTIVO}

Del conjunto de estudios previos realizados, cabe destacar ahora el detallado reconocimiento de los daños. Sus conclusiones posibilitaron contrastar las hipótesis sobre la historia del edificio y fueron decisivas en el planteamiento del proyecto de intervención definitivo

Se realizó mediante un proceso de síntesis de las informaciones obtenidas con programas específicos (incluyendo el estudio geotécnico del subsuelo y un estudio mineralógico de piedras y morteros), el examen visual directo de la degradación de los materiales y la distribución de las lesiones y la interpretación de los datos históricos sobre las transformaciones constructivas y los daños.

El análisis más detallado se concentró en el subsistema de muros y cimientos -los únicos conservados- y en los vestigios de revestimientos. En el primer caso se puso de manifiesto que los apoyos no uniformes de los muros sobre el suelo era la causa más probable de los desórdenes estructurales (el evidente desplome del muro de mediodía hizo pensar en un posible hundimiento de los cimientos, por ello se propuso su análisis y el del terreno sobre el que se asientan). En cuanto a los muros, se observó que eran de doble hoja no trabada, con algunos sillares, pero en algún sector, más parecidos a la mampostería que a la sillería, sensibles a la acción del agua, como demuestran la gran cantidad de grietas y agujeros, así como la aparente porosidad de la piedra y el mortero.

Con el estudio geotécriico-del que se derivó un informe con conclusiones y recomendaciones-, se pretendía conocer el subsuelo que soportaba la construcción, especialmente en lo referente a su estructura, a las características geotécnicas y a la presencia y dinámica de aguas subterráneas poco profundas, para definir el tratamiento más adecuado a las anomalías detectadas.

El estudio del terreno puso de manifiesto una composición geológica sedimentaria de la edad terciaria, compuesta esencialmente de margas y areniscas con niveles de yeso en la base. La estructura litoestratrigráfica es horizontal, confracturas importantes que generan relieves escalonados por desplazamiento vertical. Las capas superiores son un recubrimiento cuaternario reciente compuesto por una terraza fluvial y enclaves arcillo-detriticos con un desarrollo escalonado. La porción de terreno en la que se sitúa la iglesia es un cuerpo de marga horizontal con niveles interestratigráficos de areniscas, afectado por fracturas del tipo falla. Uno de estos niveles (de $25-30 \mathrm{~cm}$ ), que se halla muy fragmentado, conforma la base del edificio.

Para el estudio geotécnico se realizó una campaña de calas para determinar la superficie de contacto entre la base de cimentación y el terreno y para estudiar su comportamiento mecánico. Estas calas se efectuaron algunas manualmente 
-profundizando hasta la base del cimiento- y otras con maquinaria ligera-a una profundidad superior para localizar terreno apto para la recimentación si fuera necesaria-. Las calas abiertas en lugares donde no se habían realizado excavaciones o prospecciones científicas se realizaron con seguimiento arqueológico. Se hicieron ensayos de resistencia a la penetración y al esfuerzo cortante, análisis de los materiales del subsuelo in situ o en laboratorio homologado e interpretación de detalle y conjunta de todas las calas mediante perfiles específicos y generales.

No se detectó la presencia de agua, a pesar de que el tipo de terreno inducía a considerar la probable presencia de flujos de circulación lenta, con la profundidad suficiente para producir humedad en la base de los cimientos a menos de un metro por debajo del nivel del terreno actual.

El estudio del subsuelo proporcionó un dato de gran valor para el proyecto: parte de la fachada sur y gran parte del ábside se asentaba, bien cerca de esta losa arenisca, bien sobre una capa de margas inmediatamente inferior, mientras quealgunos contrafuertes apoyan sobre terrenos cuaternarios de recubrimiento. Según este estudio, la capa de roca actúa como una losa de cimentación "semifinita" y los cimientos transmiten una carga de 1,5 a $1,7 \mathrm{~kg} / \mathrm{cm}^{2}$, sobradamente admisible, que se transmite al terreno del orden de 0,5 a 0,7 $\mathrm{kg} / \mathrm{cm}^{2}$.

Esta baja presión fue valorada como un posible factor negativo, ya que pueden ser superiores las presiones en sentido contrario producidas por las margas expansivas en contacto con el agua filtrada por las grietas de la arenịsca. Esta diferencia puede producir inestabilidad, ya que la losa puede subir y bajar, aunque siempre homogéneamente.

A partir del estudio se llegó a la conclusión de que en las zonas en que el edificio se apoya bien no existe ningún problema, pero sí allí donde el muro coincide con los bordes de la losa, ya que se producen acumulación de tensiones y basculación del muro hacia el exterior. En las zonas de cimentación mixta (marga, arenisca e incluso recubrimiento cuaternario, como por ejemplo el contrafuerte del ábside), existe peligro de asentamientos diferenciales en períodos de alternancia de sequedad y humedad de las margas. Un efecto negativo adicional es latracción que pueden producir los contrafuertes bien asentados en la fábrica cuando su base de marga desciende. Los efectos pueden ser rompimientos, abombamientos y basculaciones.

En cuanto a los efectos sísmicos, después de consultar el catálogo general de seísmos de la Península Ibérica publicado por el Instituto Geográfico Nacional, se llegó a la conclusión de que el único movimiento de intensidad suficiente para afectar a la estructura de la iglesia de manera significativa fue el que se produjo el 2 de febrero de 1428. No disponemos de datos ni para afirmar ni para descartar la incidencia de este movimiento en la patolo- gía que afectaba al edificio, pero los mapas existentes sobre los efectos que el terremoto produjo en la zona permiten pensar que, efectivamente, ésa pudo ser la causa del desplome de los muros de la iglesia.

El estudio de la naturaleza petrográfica de piedras y morteros se realizó mediante la difracción por rayos $\mathrm{X}$ y microscopía de láminas finas. La piedra arenisca (de cemento de carbonato cálcico), resultó muy porosa y alterable, a pesar de su resistencia mecánica alta. El mortero de unión o de fábrica era de cal, también porosa y con presencia de yeso, factor de alteración grave no presente en los morteros de revestimiento, la alta retracción de los cuales, asimismo, les hace poco solidarios con la piedra.

Las recomendaciones del estudio físico-constructivo de caraa laintervención posterior fueron éstas: como actuación mínima, recalzar los contrafuertes y el sector del muro con cimentación mixta (ábside y muro lateral sur), hasta apoyarlos sobre la roca arenisca similar a la losa y, en cualquier caso, a una profundidad suficiente para evitar la incidencia desfavorable del agua, y reducir el efecto de las aguas pluviales (cubrir el edificio, pavimentar el entorno en una zona de 2 a 3 metros y proteger las paredes). De esta manera no se garantizaba la inmovilización del edificio, pero sí la reducción de los movimientos "de manera notable y quizá suficiente".

Como actuación máxima, se recomendaba recalzar todo el edificio, incluidos los contrafuertes, mediante pozos que derivasen las cargas a más profundidad (mínimo 2,5 metros), para evitar el efecto de la variación del grado de humedad y concentrar las cargas para neutralizar los efec-

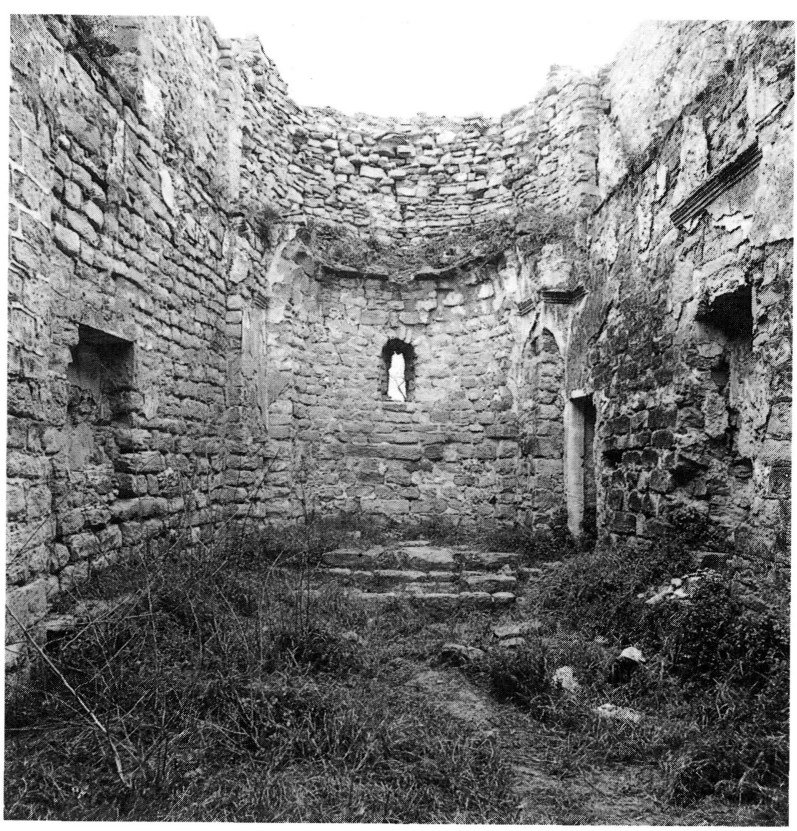

Interior de la iglesia antes de iniciarse los trabajos de restauración ( 9 de marzo de 1993). 
tos expansivos. Y, en cualquier caso, trabar las hojas de los muros y rejuntar los paramentos con un mortero adecuado, es decir, compatible con los morteros pre-existentes, de escasa retracción y manejabilidad (concretamente, se recomendó un mortero de color blanco, resistente a los sulfatos -presentes en la mineralogía de las piedras de los muros-, sin retracción, de una consistencia adecuada para su colocación en obray no muy complejo en su confección).

\section{CRITERIOS DE LA INTERVENCIÓN ARQUITECTÓNICA}

Cuando en abril de 1993 se inició la intervención, el ayuntamiento contaba ya con un proyecto de restauración realizado en 1988, que, entre otras decisiones discutibles, preveía la eliminación del cuerpo superior moderno. Los resultados de los estudios previos citados aconsejaron la redacción de un nuevo proyecto, más en consonancia con la lectura histórica.

La actuación, en consecuencia, se planteó como objetivos, recuperar la autenticidad arquitectónica del monumento, potenciar su capacidad informativa (hacer del monumento una crónica de su evolución a lo largo de la historia) y fortalecer su capacidad de significación colectiva. Los criterios generales fueron los siguientes: devolver a la ruina su condición arquitectónica mediante la recuperación del espacio interior del monumento y la posibilidad de ser utilizado (tanto el edificio como el entorno); recuperar episodios formales y constructivos de la historia del edificio, sin que prevaleciera una época en detrimento de las otras (por tanto, no se eliminarían las superposiciones postrománicas); hacer más legible la evolución del uso, la forma y los sistemas constructivos del edificio, sin renunciar incluso a la clara manifestación de los signos que delatan procesos de orden patológico. Desde un punto de vista formal, había que matizar la presencia de elementos morfológicamente y estilísticamente actuales, para no violentar la imagen exterior que percibiría el espectador.

Respecto a los criterios de carácter estructural, en contradicción también con las previsiones del proyecto de 1988, se decidió adoptar la solución de recalzamiento mínima, para reducir sus costos, evitar sacrificios innecesarios al subsuelo y alterar al mínimo el equilibrio alcanzado en los últimos cinco siglos entre el monumento y el terreno. Esto suponía, fundamentalmente, poner en carga los contrafuertes, garantizando su contacto con los muros y la transmisión de presiones a los terrenos adecuados; reducir el efecto de las aguas pluviales protegiendo los muros y el entorno inmediato del monumento mediante drenaje y aceras; trabar los dos hojas externas de los muros, rellenar agujeros y rejuntar profusamente con el mortero adecuado, sin utilizar consolidantes ni hidrofugantes, y diseñar las nuevas estructuras con una cierta independencia de los muros preexistentes; no zunchar el edificio para permitirle los movimientos que se puedan producir en los períodos de alternancia humedad-sequedad.

\section{DESCRIPCIÓN DE LAS OBRAS}

Tras la intervención, la iglesia ha recuperado, por un lado, los rasgos característicos de la construcción románica: la planta, la volumetría del ábside con su cubierta de horno, la cornisa exterior de piedra, que delimita la altura primitiva de la construcción medieval, y la bóveda de cañón de la nave, recuperada de modo conceptual. Por su parte, el nuevo cuerpo superior explica su propia evolución: ha recuperado los huecos que tenía en el siglo XV por el lado meridional, pero ha continuado cegado por el de tramontana, por los muros que lo tapiaron en el siglo XVII.

Este cuerpo alto se ha hecho accesible a través de una escalera de caracol con un primer tramo de madera y el resto de hierro. Una vez arriba, se puede bordear el extradós de la bóveda por un pasillo formado por plataformas de vidrio, adosado al muro de mediodía.

Para hacer compatibles la reconstrucción de este piso alto y la recuperación del espacio original románico, la bóveda se proyectó con materiales ligeros: estructura metálica y entablado de madera de cedro americano por el intradós, y madera y cobre por el extradós. Su forma y dimensiones son posiblemente como las de la original, pero no tiene contacto aparente con los muros. Así, el espectador puede observar mejor el desplome de éstos e intuir la caída de la bóveda que se produjo en el siglo XV. Esta separación entre bóveda y muros es aprovechada para que la luz natural y artificial que atraviesa las plataformas de vidrio bañe los lienzos de piedra y remarque la sensación de ligereza de la bóveda.

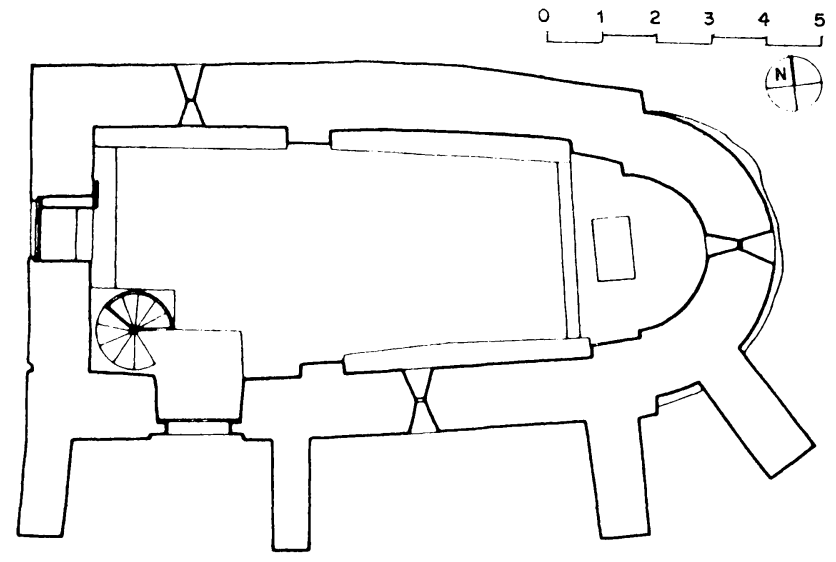

Planta de la iglesia, después de la restauración. 


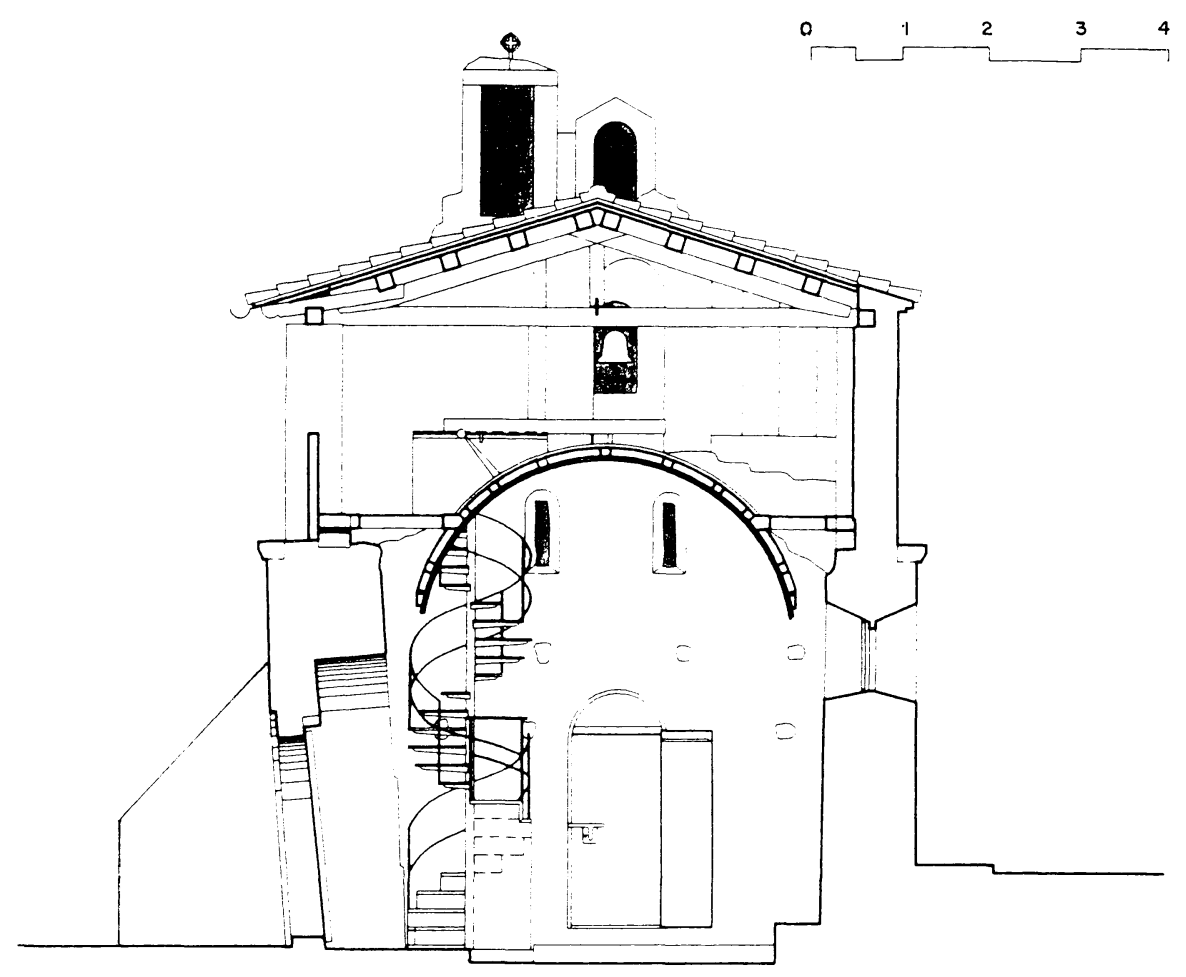

Sección transversal y alzado interior del muro de poniente.

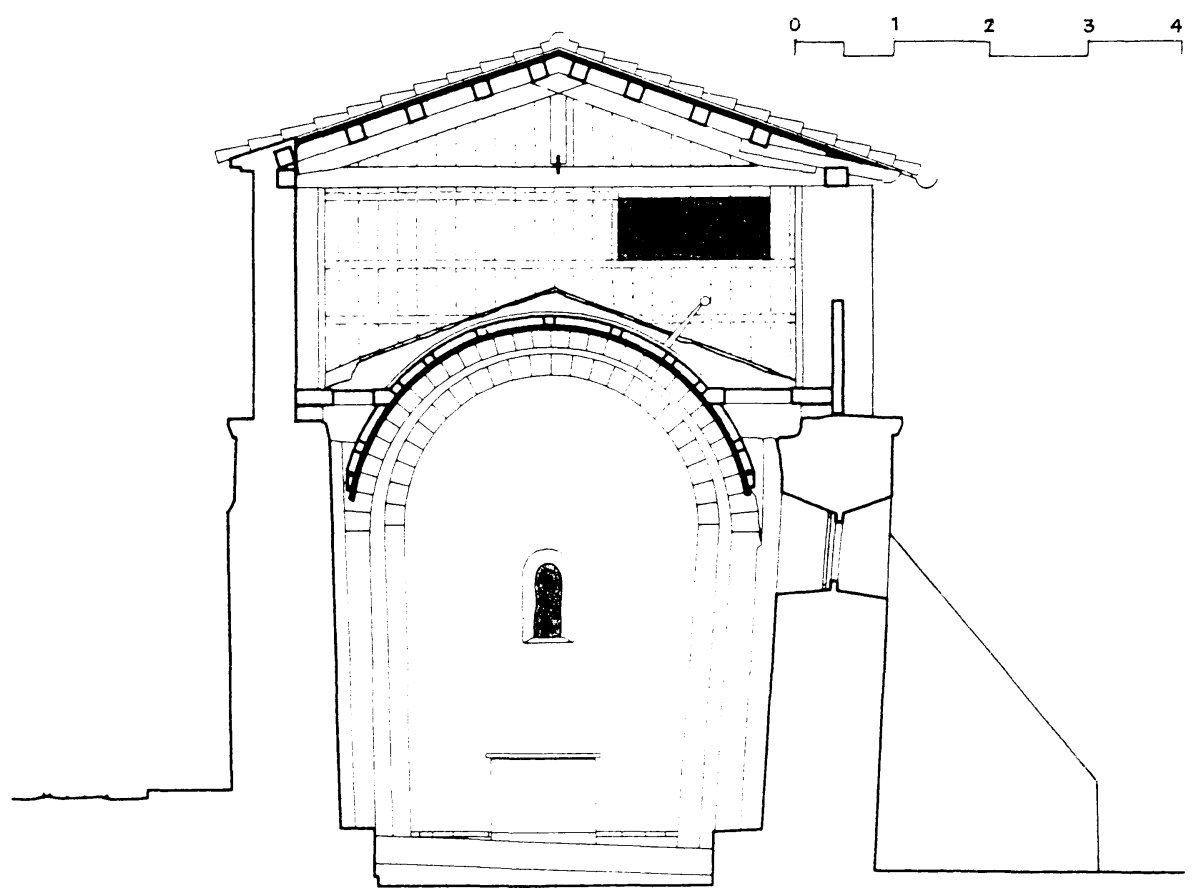

Sección transversal y alzado interior del ábside.

Para construir la bóveda de la nave se formó una estructura metálica con nueve perfiles de acero (IPN-16), rectos en los extremos y curvos en la zona central, siguiendo la forma de la bóveda, colocados a una distancia de 1 metro. Los perfiles se situaron sobre soportes de hormigón, y en los puntos de contacto se colocaron unas placas de hierro embebidas en el hormigón; en los soportes del sector norte las omegas metálicas fueron soldadas a estas placas de hierro. En los soportes del lado sur se intercaló entre la estructura y las placa de hierro una capa de neopreno de 5 $\mathrm{mm}$ de grueso para permitir el movimiento de la estructura y disminuir así las cargas horizontales. En el grueso de los 
perfiles metálicos, empotrados entre sus dos alas y siguiendo la curvatura de la bóveda, se colocaron tacos de madera de pino, como soporte de los revestimientos de la bóveda. El interior se formó con láminas de madera de

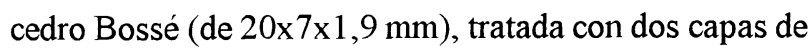
barniz de poliuretanoy una última capa delaca, que facilitará la restauración futura de la madera, si es necesaria. Las láminas se fijaron a los tacos mencionados, bajo los perfiles y se colocaron perpendicularmente a ellos, en sentido longitudinal.

Sobre las láminas de cedro y en el grosor de los perfiles, se colocó aislamiento térmico de lana de fibra de vidrio de $8 \mathrm{~mm}$ de grosor. Encima de los perfiles se colocó, también fijado en los tacos de madera, conglomerado machihembrado hidrofugado de $28 \mathrm{~mm}$ de grosor, como base de la cara superior de la bóveda de la nave. Encima, se colocó tablón de D.M. de $7 \mathrm{~mm}$ de grosor, para dar mayor continuidad a la curvatura de la bóveda. Finalmente, como revestimiento superior, clavado sobre el D.M. se colocaron módulos de cobre de $180 \times 60 \mathrm{~cm}$ y $0,6 \mathrm{~mm}$ de grosor. Se situó una lámina de butilo de $0,8 \mathrm{~mm}$ de grosor para evitar el contacto entre el cobre y la estructura de acero.

El pasillo de vidrio que bordea el extradós de la bóveda, en el piso alto, se formó de la siguiente manera: entre los perfiles metálicos de soporte de la bóveda, se soldaron, en el alma, otros perfiles (IPN-10), en sentido perpendicular, coincidiendo con los lados de las dos pasarelas que hay en los laterales de la bóveda. Sobre ellos, se soldaron perfiles en $\mathrm{L}$, encima de los cuales se colocó un separador de neopreno de $10 \mathrm{~mm}$ de grosor, de color blanco, en el que

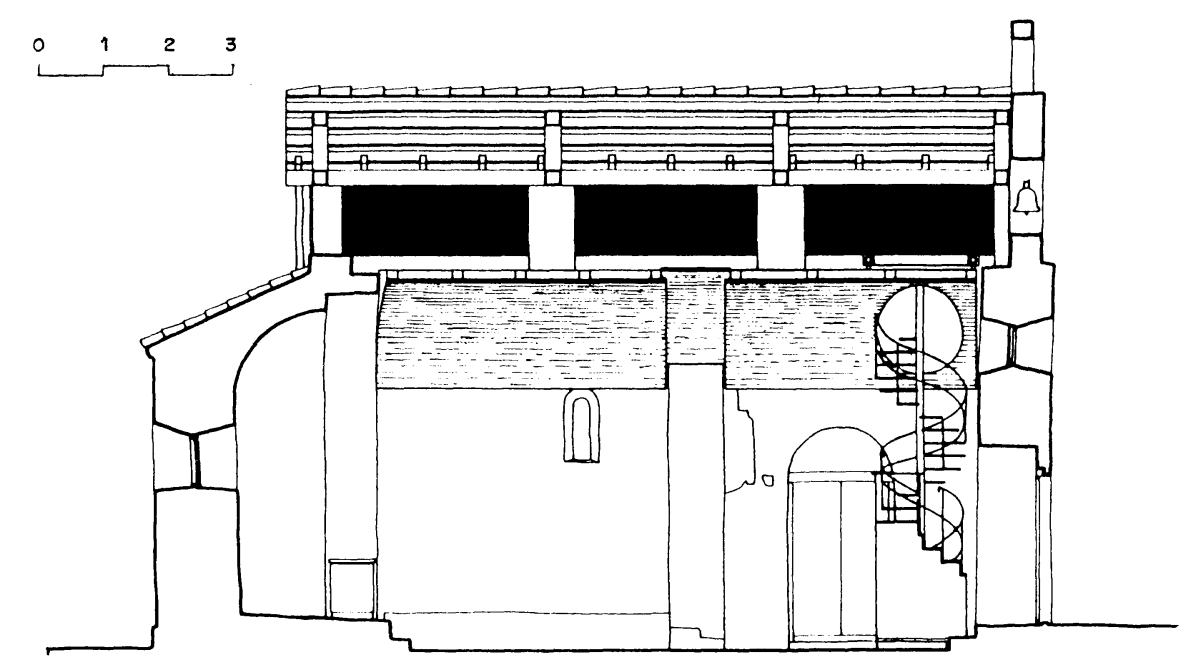

Sección longitudinal y alzado interior del muro de mediodia.

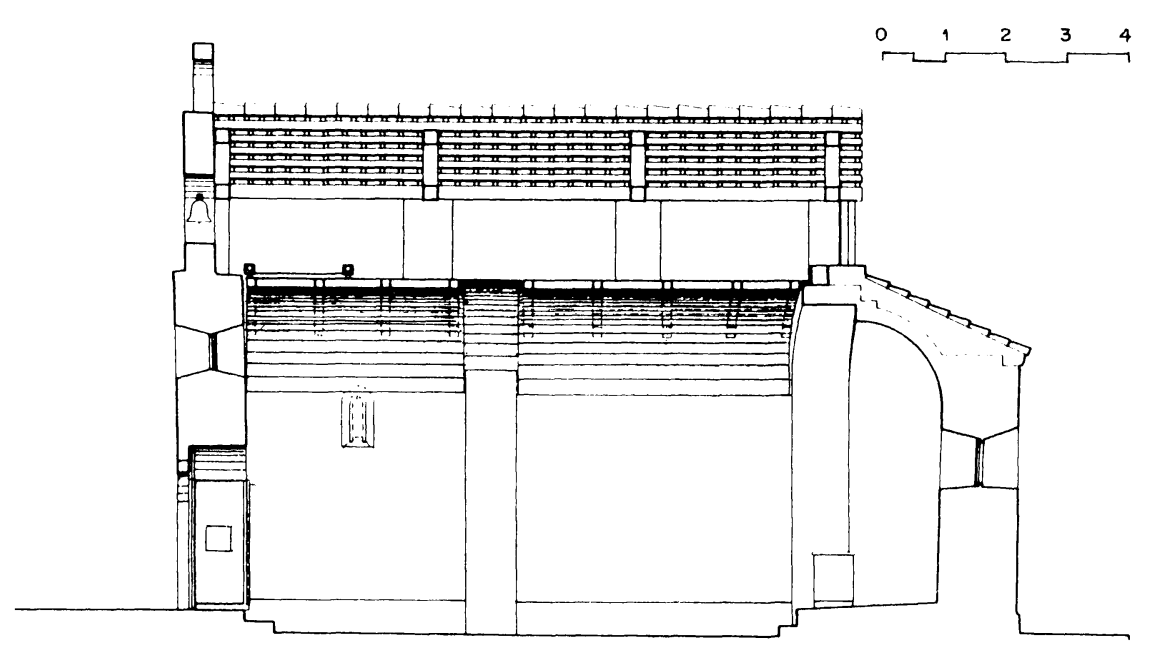

Sección longitudinal y alzado interior del muro de tramontana. 
apoyarían directamente los vidrios, piezas de aproximadamente un metro cuadrado (vidrio Stadip $10+6+6 \mathrm{~mm})$, con un butiral blanco y otro transparente. En las separaciones entre vidrios se colocó un pavimento de madera de Melis tratada con un producto fungicida.

La nueva cubierta del cuerpo superior sigue un modelo tradicional de cuchillos, con algunas variantes propias de la comarca. Se hizo con madera de pino, secado y tratado con sales hidrosolubles al autoclave, para resistir la intemperie. Esta estructura consta de armaduras (sección de $18 \times 22 \mathrm{~cm}$ ), ménsulas (sección de $20 \times 20 \mathrm{~cm}$ ), zunchos (sección de $15 \times 15 \mathrm{~cm}$ ) y latas (cabios) (sección de $7 \times 4,5 \mathrm{~cm}$ ). Sobre las latas de madera se colocaron baldosas cerámicas. Las que forman los voladizos norte y sur fueron mojadas en cal, formando rombos. En la vertiente meridional se formó un potente sobradillo que desagua en un canal de cobre, para proteger al porche abierto. Encima de las baldosas se hizo una solera de $5 \mathrm{~cm}$ de grosor con hormigón de cemento portland, hecho en obra

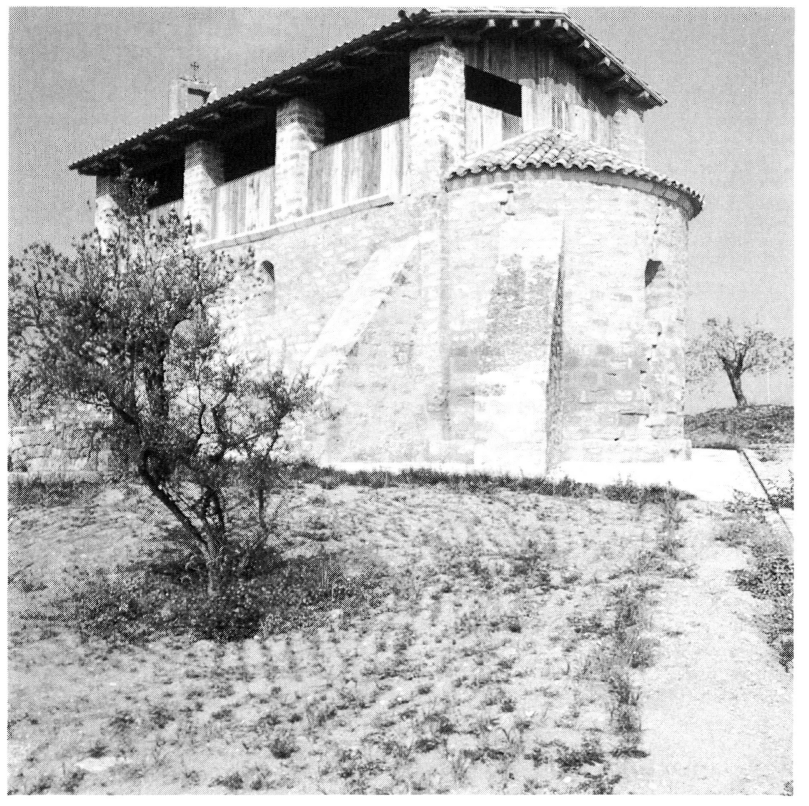

La iglesia vista desde el sudeste, después de la restauración (4 de octubre de 1995).

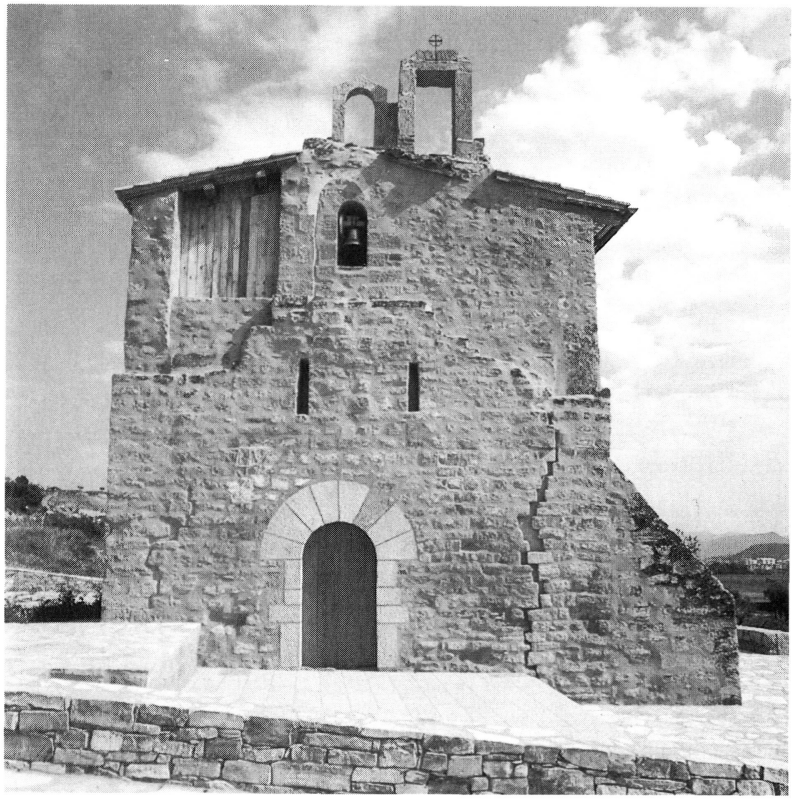

Fachada de poniente, despu'es de la restauración(4 de octubre de 1995).

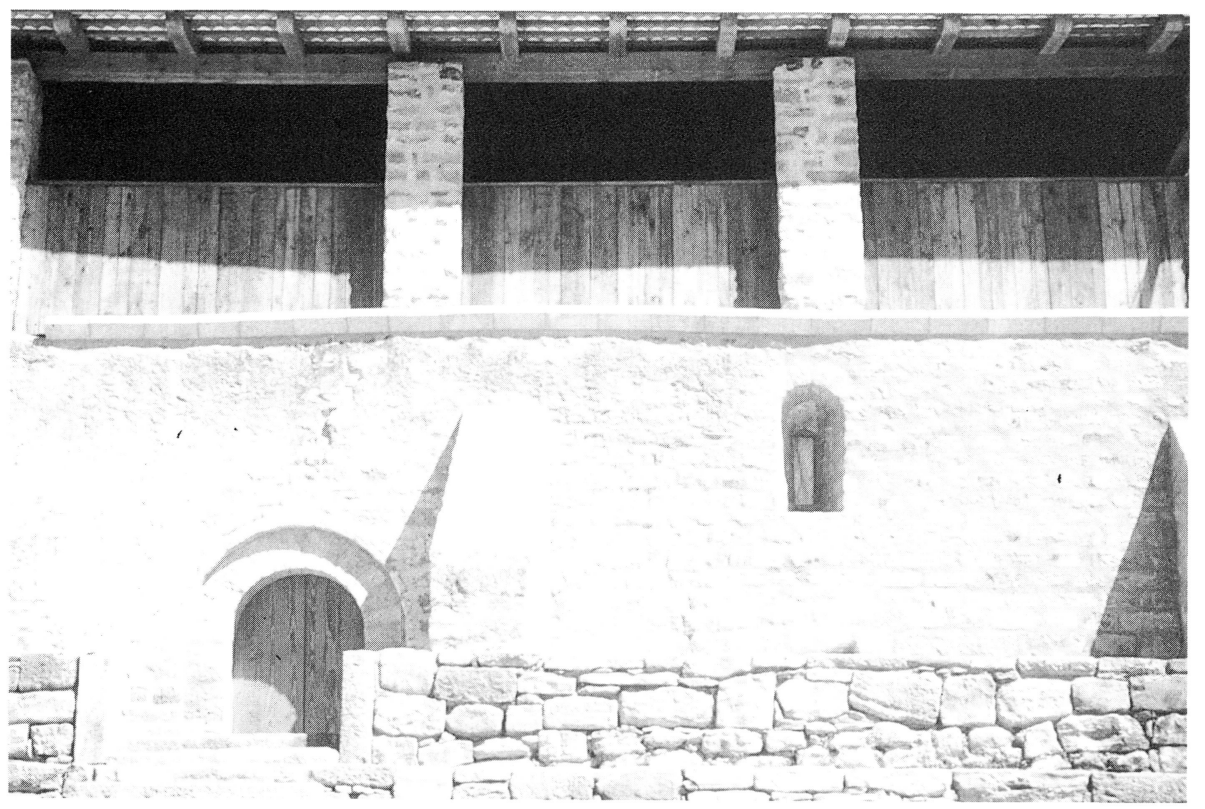

Detalle de la fachada de mediodia, despues de la restauración (27 de abril de 1995). 
y mallazo $30 \times 15 \mathrm{~cm}$, de $5 \mathrm{~mm}$ de díametro, Encima, se colocó la teja árabe recuperada. Los cerramientos ligeros de este cuerpo se han hecho con madera de encofrar ya usada.

Respecto a la cubierta del ábside, por encima de la bóveda se hizo una solera, de grosor variable para dar la pendiente, con hormigón hecho en la obra (con cemento tipo I-35/A SR-MR) y mallazo de $30 \times 15 \mathrm{~cm}$ de díametro $5 \mathrm{~mm}$.

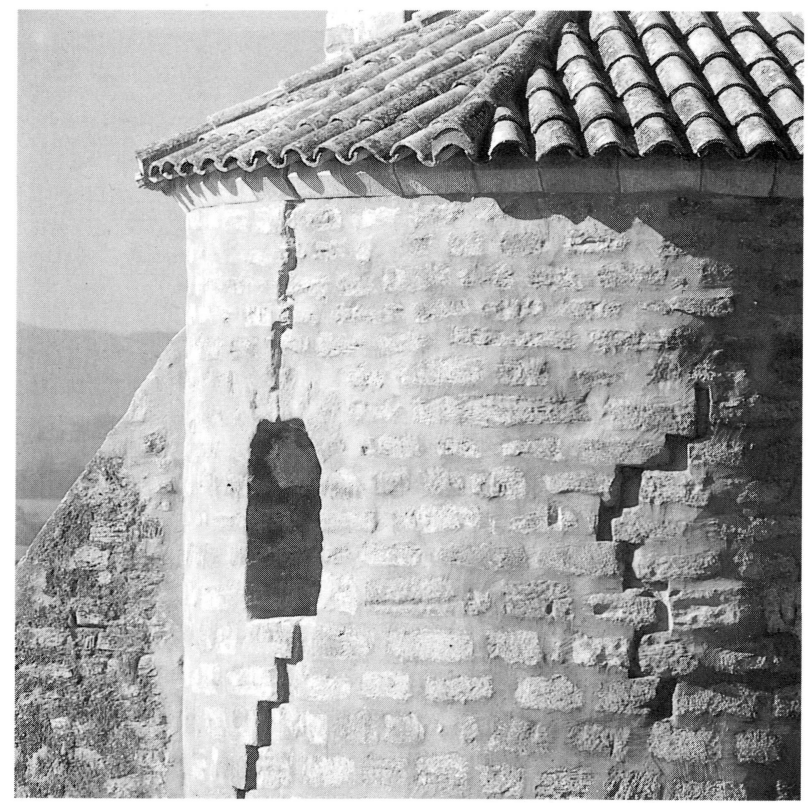

Se han conservado las huellas de los diversos avatares y patologías que ha sufrido el edificio (27 de abril de 1995).

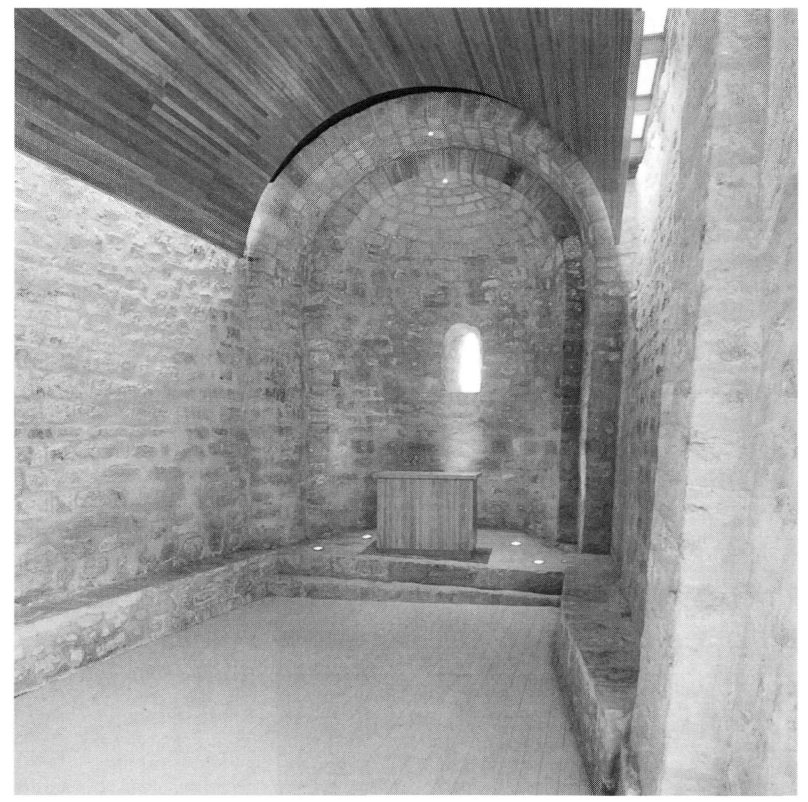

Interior de la iglesia después de la restauración. Puede observarse el desplome del muro de mediodía (4 de octubre de 1995).
Encima de ella se fijó, con mortero de cemento, teja árabe de las mismas características que la utilizada en la cubierta de la nave.

La bóveda del ábside, así como los contrafuertes, el arco triunfal y las cornisas se reconstruyeron con sillares de piedra arenisca fijados con mortero de cal y cemento tipo I-35/A SR-MR (con la dosificación en peso $1: 1,2: 15: 0,1: 1,8)$. Se optó por este tipo de cemento, pues-

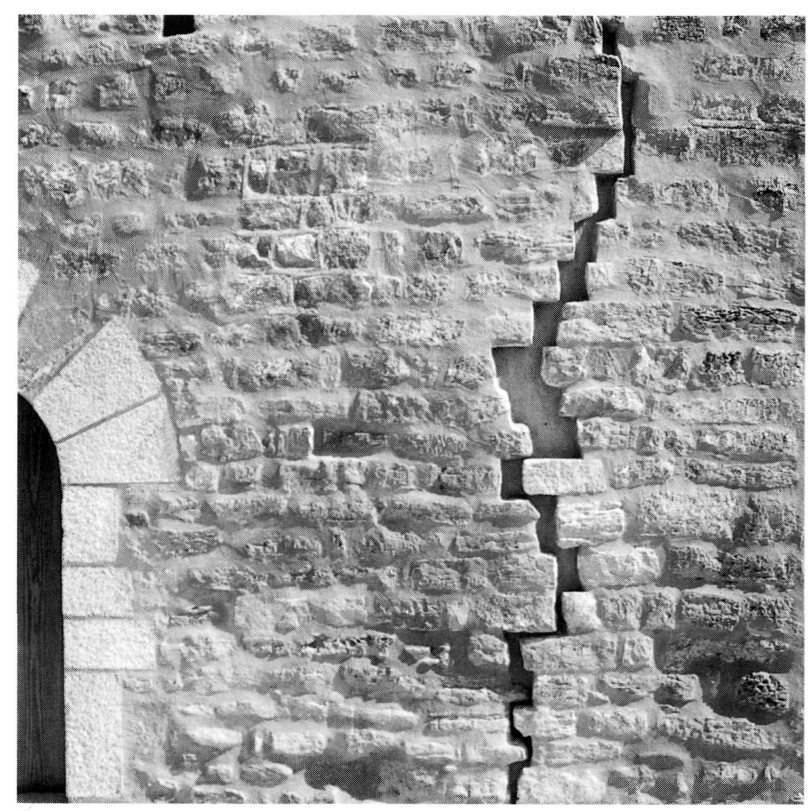

La grieta que recorre verticalmente la fachada de poniente (4 de octubre de 1995).

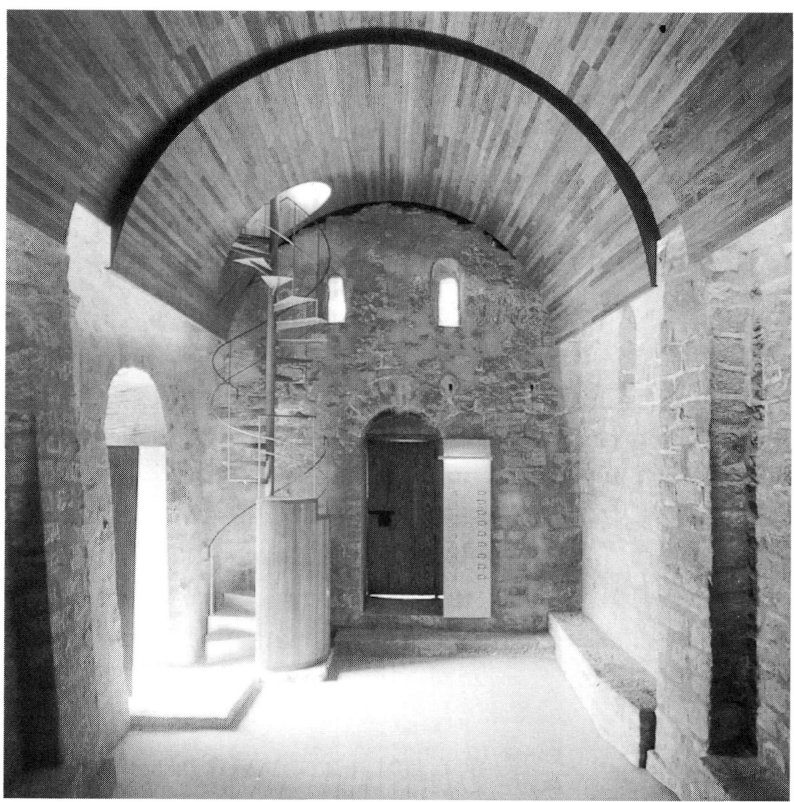

Interior de la iglesia después de la restauración (4 de octubre de 1995). 


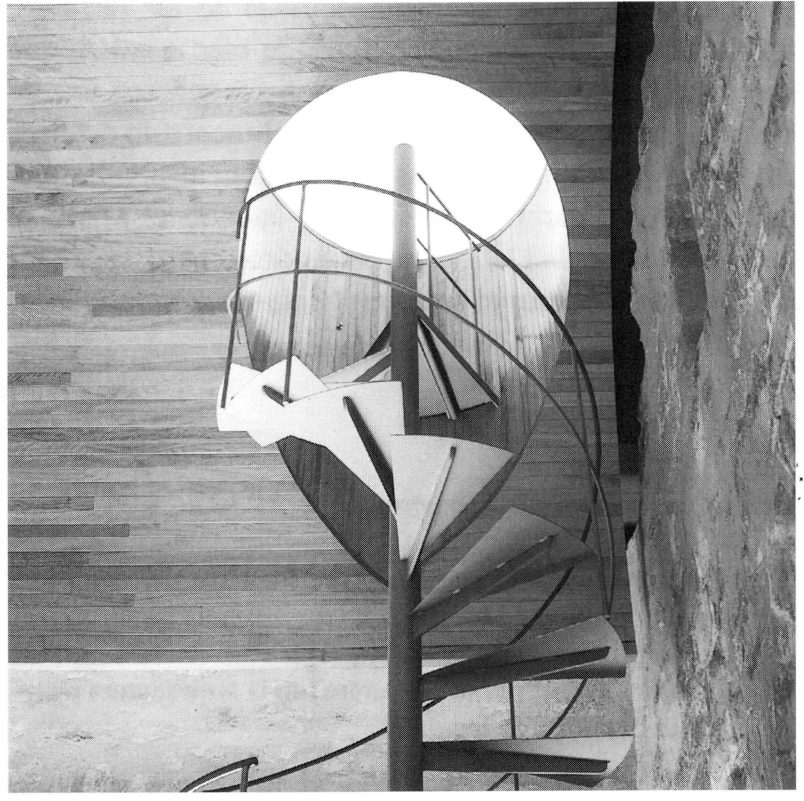

Ietalle de la escalera de caracol por la que se accede al antiguo granero (4 de octubre de 1995).

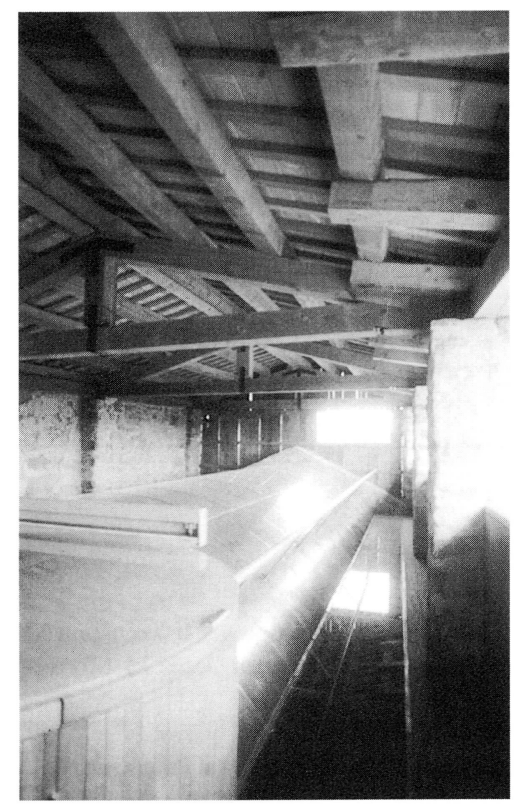

Vista del espacio superior, hacia levante (1 de junio de 1995).

to que el análisis de la piedra y los morteros existentes en la obra nos advirtió que contenian yesos y que podía ser perjudicial para la piedra utilizar cemento portland. Para reducir la cantidad de agua de los morteros y evitar fisuras de retracción, sin que la pasta dejara de ser moldeable, se utilizó un suplerfluidificante. Para el rejuntado visto de los sillares se utilizó un mortero parecido, del tipo I-35/A SR MR, pero con colorantes (Siena natural 19-M y Almagra).

(c) Consejo Superior de Investigaciones Científicas Licencia Creative Commons 3.0 España (by-nc)

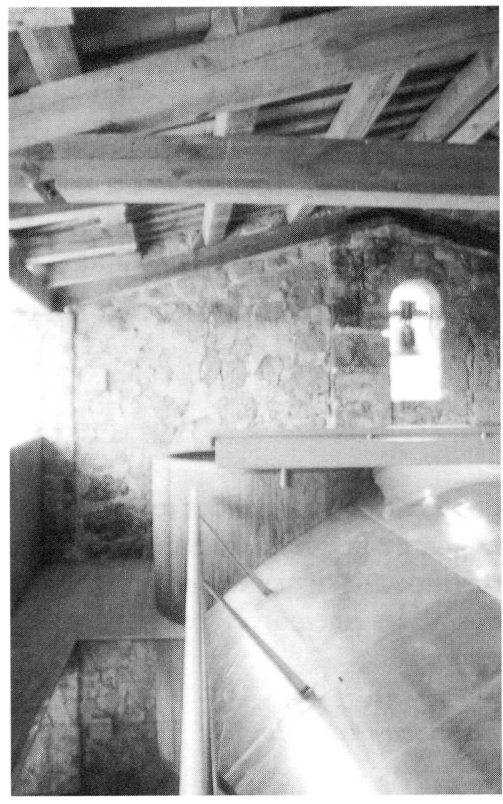

Espacio superior. Trasdós de la bóveda reconstruida y corredor (1 de junio de 1995).

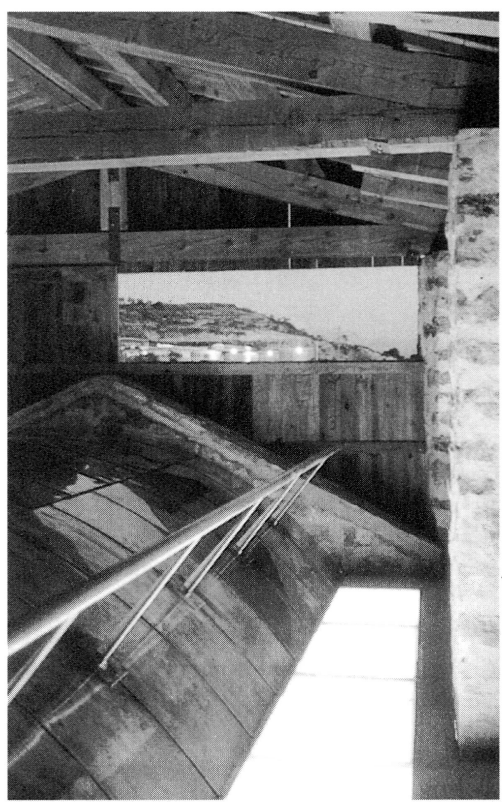

Iluminación nocturna del espacio superior (1 de junio de 1995).

El pavimento de la nave se hizo a base de piezas alargadas de piedra arenisca cortada con sierra en piezas alargadas de $10 \mathrm{~cm}$ de ancho, $3 \mathrm{~cm}$ de grosor y largos de 50,60 y $70 \mathrm{~cm}$., mientras que el ábside conserva el pavimento de losas de piedra del siglo XVIII.

Al restaurar y consolidar los muros, las grietas se limpiaron y se llenaron de mortero y piedra, pero se cosieron sólo por 
dentro; por fuera se dejaron aparentes, con la voluntad de que quedaran como testimonio de la catástrofe sísmica que afectó al edificio en el siglo XV. Las obras casi no hicieron variar el aspecto de la fachada de poniente de la iglesia, con sus cuatro espadañas superpuestas. En esta fachada, se abrió la puerta del siglo XIV, se consolidó el conjunto de espadañas y se coloco una campana pequeña. Encima de la espadaña grande se colocó una cruz de hierro.
En el entorno, se recuperaron algunas de las terrazas, separando sus ámbitos con muretes de piedra caliza que sirven a la vez de asientos, y se crearon dos accesos, uno de ellos con una rampa, para posibilitar el recorrido exterior sin barreras arquitectónicas. En honor al nombre del lugar, se replantaron veinte olivos -cuando se inició la intervención había algunos almendros, pero sólo tres olivos-, dispersos por el cerro en el que se alza la iglesia.

\section{NOTAS}

(1) Los trabajos técnicos y científicos realizados con motivo de la restauración de la iglesia de Sant Jaume Sesoliveres se refieren a los aspectos siguientes (no se incluyen los dictámenes previos y las memorias relativas a la excavación arqueológica):

Análisis histórico-arqueológico:

- Estudio de restos humanos (antropología física).

- Estudio ceramológico.

- Clasificación y estudio de monedas.

Análisis histórico-documental:

- Estudio de las fuentes documentales de la iglesia.

Análisis histórico-artístico:

- Inventario y ánalisis artístico de elementos de piedra hallados en las excavaciones.

- Inventario de iglesias catalanas del camino de Santiago.

Paralelismos cronológicos, arquitectónicos y estilísticos.
Análisis histórico-constructivo:

- Aproximación a la evolución constructiva del edificio a través del estudio de los materiales, sistemas constructivos y huellas de patologías.

- La tradición del "porxo" (granero) en la arquitectura popular de la comarca de Igualada.

Análisis fisico-constructivo:

- Datos geográficos y ambientales del lugar.

- Determinación de la composición, análisis y diferenciación geoquímica entre morteros de diferentes etapas constructivas.

- Estudio geotécnico del terreno.

Análisis arquitectónico:

- Levantamiento topográfico del entorno.

- Levantamiento de planos del edificio.

\section{Ficha Técnica}

Realización: Diputación de Barcelona (Servicio de Patrimonio Arquitectónico Local). 1994-1995

Dirección general: Antoni González Moreno-Navarro

Investigación histórica: Arqueología: Alberto López Mullor, Àlvar Caixal Mata, Xavier Fierro Macía. Antropología física: Anna M. Mestre. Numismática: María Clua. Documentación, historia del arte y de la construcción: Anna Castellano, Raquel Lacuesta, Josep M. Moreno, M. José Sureda, M. Antònia Carrasco

Análisis físico-constructivo: Dirección y coordinación: José Luis González, Albert Casals, Alejandro Falcones. Universitat Politècnica de Catalunya (UPC). Análisis de materiales: Joan Ramon Rosell, Àngel Arricivita (UPC). Estudio geotécnico: Antoni Batlle, Pere Mascareñas.

Intervención arquitectónica: Arquitecto: Antoni González Moreno-Navarro. Colaboradores: Xavier Guitart, arquitecto, Jaume Bassas, arquitecto técnico. Constructor: Joan Closa Serra (Copons, Barcelona).

Trabajos especiales: Museización: Olga de la Cruz, Lourdes Borrell. Diseño gráfico: Quim Boix.

Fotografias: Montserrat Baldomà. Dibujo: Txetxu Sanz. 